\title{
A educação socioambiental e o princípio da responsabilidade para estudantes privados de liberdade
}

\section{Socio-environmental education and the principle of responsibility in the education of students in prison and detention}

\author{
Ires Aparecida Falcade-Pereira*
} Araci Asinelli-Luz

\begin{abstract}
Resumo: Pensar a educação para estudantes privados de liberdade nos dias atuais só faz sentido se for dotada de significado enquanto processo de reinserção social e conectada com as transformações socioambientais e responsabilidade frente à sustentabilidade do planeta. Este artigo retrata, em essência, uma reflexão sobre a prática pedagógica no contexto prisional, a partir da educação socioambiental. Evidenciado pelo consumismo e individualismo, o momento nos leva a pensar o princípio da responsabilidade como necessidade de transformação, pela educação, na privação de liberdade, e a encarar as práticas relativas ao agir humano como desafios possíveis. A educação no Sistema Penitenciário exige postura crítica e inovadora, de forma a propiciar, por meio de atitudes e prática pedagógica, a transformação social. Mesmo privado/a de liberdade, o/a estudante deve buscar o relacionamento harmonioso entre todas as formas de vida existentes no planeta, percebendo-se como parte desse processo. A retomada da capacidade humana em articular as ideias e ações que poderão transformar as degradações atuais em medidas práticas sustentáveis, permitindo a continuidade da vida no planeta e, principalmente, a própria existência humana, faz parte da metodologia do ensino de Biologia vivenciado no CEEBJA Mario Faraco, no estado do Paraná. Fazer esta reflexão junto aos/ as estudantes privados/as de liberdade mobiliza a tomada de postura diferente frente a si próprio, ao planeta e à sociedade como um todo.
\end{abstract}

Palavras-chave: Educação socioambiental. Princípio da responsabilidade. Sustentabilidade. Estudantes privados de liberdade.

\begin{abstract}
Thinking about the education of students who are prison or detention nowadays only makes sense if it has meaning as a social reintegration process and is connected to the socio-environmental transformations and responsibilities facing the sustainability of the planet. This paper portrays, in essence, reflection about pedagogical practice in the prison context from the standpoint of environmental education. In this time of consumerism and individualism, we are lead to think about the principle of responsibility as a necessity in the transformation through education, in the deprivation of liberty, and to look at the practices related to human activity as possible challenges. Education within the penal system demands a critical and innovative posture, providing the possibility of social transformation through attitudes and pedagogical practice. Even when deprived of liberty, the student should seek a harmonious relationship between all existing ways of life on the planet, perceiving them as part of this process. The resumption of the human capacity to articulate the ideas and actions that can transform the current degradations in practical, sustainable measures, allowing the continuity of life on the planet, and specifically human existence, is part of the Biology teaching method carried out in the CEEBJA Mario
\end{abstract}

\footnotetext{
* Mestranda em Educação, Cognição e Desenvolvimento Humano pela Universidade Federal do Paraná (UFPR). $<$ E-mail: iresfalcade@hotmail.com>.

** Doutora em Educação. Professora do Programa de Pós-graduação da UFPR. E-mail: <asinelli@ufpr.br>.
} 
Faraco, in the state of Paraná. Reflecting on this with students deprived of liberty mobilizes a different posture against itself, the planet and society as a whole.

Keywords: Socio-environmental education. Principle of responsibility. Sustainability. Students deprived of liberty..

\section{Introdução}

Propiciar uma educação que desperte o interesse e a motivação para aprender do/a estudante privado/a de liberdade não é tarefa fácil e exige profissionais qualificados e compromissados. Os desafios que a prática pedagógica coloca no contexto prisional, aliados à crise de recursos naturais pela qual passa o planeta e à crise existencial que os/as estudantes privados/as de liberdade trazem à sala de aula, nos aproximam do Princípio da Responsabilidade desenvolvido por Hans Jonas (1996). Essa aproximação é facilitada pela discussão propiciada pelos temas pertinentes à educação socioambiental em aulas de Biologia.

Atualmente sofremos as consequências da falta de cuidado com a natureza em especial e como um todo sistêmico. Nossa sobrevivência no planeta é o carro chefe das discussões na mídia. O ser humano é a espécie de vida do contexto existencial de Gaia, nossa mãe Terra, que tem a capacidade para decidir e articular suas ideias, pensamentos e ações.

Até pouco tempo, o homem/mulher agia como se fosse o centro do universo. Assim pensando, imaginou que as florestas e as águas jamais teriam fim. Considerando-se o centro do universo e do nosso planeta, o mais importante, o supremo destacado pela inteligência, usou e abusou da destruição em nome da construção, jogou esgoto nos rios e mares, imensos depósitos de lixo na natureza, imensidão de gases poluidores na atmosfera. Não imaginou que esses recursos poderiam um dia acabar, ou voltarem-se contra si pondo em risco sua própria sobrevivência e existência.

O fato de pensarmos hoje sobre nossos desafios em repararmos os danos causados, em preservar as espécies e garantir a biodiversidade denota um apelo ético que explora todas as facetas da nossa responsabilidade e da realidade numa era tecnológica e da informação. Vale lembrar que, no risco de extinção, encontra-se também o ser humano, que neste momento sofre como vítima, porém está penalizado como mentor, consequência de suas atitudes, deparando-se com as inúmeras catástrofes naturais. Portanto, este artigo tem como objetivo refletir sobre a prática pedagógica no contexto prisional a partir da educação socioambiental nas aulas de Biologia.

\section{A educação socioambiental e o Princípio da Responsabilidade}

Hans Jonas, filósofo alemão, em sua obra "O Princípio da Responsabilidade: ensaio para uma ética para a civilização tecnológica”, publicada em 1979 (JONAS, 2006), tem o propósito de explicitar os aspectos principais do seu projeto. Ele explica o que seria uma nova ética fundada no princípio da responsabilidade, ao mesmo tempo em que critica a utopia política na onipotência virtual da tecnologia moderna fundada nas ciências naturais. Sua ideia central de ética - a idéia de dever e de responsabilidade do 
agente humano relativamente à natureza e ao futuro das próximas gerações humanas sobre a Terra (JONAS, 2006) - equipa o agir humano, alterando essencialmente 0 horizonte e as coordenadas espaciais e temporais em que se insere e onde se desdobram os efeitos desse agir.

Atualmente o ser humano é sujeito e, ao mesmo tempo, objeto do seu agir. Tomamos consciência de que progressivamente todas as mutações se voltam para o próprio ser humano e que o prolongamento da vida humana permeia e exige um monitoramento do seu próprio comportamento. Sabendo que pode pôr em perigo sua própria essência e existência, o homem precisa, urgentemente, ser estável e responsável em suas ações (agir humano).

Para Jonas (2004), as transformações do agir humano mostram a fragilidade da vida e abrem espaço para a nossa civilização tecnológica, referindo-se à realidade humana em si mesma, utilizando-se da humanidade global como ponto de referência.

Giacóia Júnior (1996) reconhece à natureza o direito próprio e a significação ética autônoma, independentemente da sua condição de meio para a satisfação das necessidades e desejos humanos. Isso significa abandonar a postura tradicional que considera o homem como o ápice da natureza e coroa da criação, servindo de fundamentação metafísica à ética, que reconhece como dever a preservação das condições sob as quais se pode, inclusive, manter inalterada a essência do humano.

Agir, do ponto de vista do imperativo ora anunciado, implica lembrar que se é admissível que possamos arriscar nossa própria vida, não estamos legitimados ou autorizados a fazê-lo quando se trata de pôr em risco a vida da humanidade. Desse ponto de vista, a simples existência de autêntica vida humana sobre a Terra apresenta-se como um valor, e a preservação das condições dessa existência como um dever a ser levado imperativamente em conta pelas novas dimensões do agir humano. Quando nos referimos à ética socioambiental, nos referimos a uma ética prática, manifestada efetivamente na conduta do ser humano livre.

Temos ciência de que a tecnologia utilizada não é eticamente neutra, nem em relação ao ambiente, nem em relação à natureza humana, considerando assim a natureza como objeto da responsabilidade humana, originando uma comunidade com consciência planetária na qual permeia interações com dimensões globais que interferem na vida de cada indivíduo.

Para Hans Jonas (1996), o princípio da responsabilidade, ao se referir ao ser humano, expressa a sua relação intrínseca com a natureza e, consequentemente, com o destino das próximas gerações.

Faz-se imprescindível uma responsabilidade coletiva, tendo a preocupação básica sobre os efeitos remotos, cumulativos e irreversíveis da intervenção tecnológica sobre a natureza e sobre o próprio ser humano, sabendo que há o perigo de ocorrer a desfiguração da natureza e do próprio ser humano em função de seu próprio poder. Temer e reverenciar a natureza são necessários em função da preservação da própria existência. É importante lembrar que a natureza possui direito e significação própria, e que não estamos autorizados a pôr em risco a vida da humanidade.

A vida é o valor maior da humanidade, e a sua preservação e condições de existência é um dever ético coletivo, o qual deve ser preservado por meio de políticas públicas adequadas.

Assim sendo, o direito ambiental regulamenta a ação humana sobre os 
ambientes através de princípios e normas reguladoras das atividades humanas que, direta ou indiretamente, possam afetar a sanidade do ambiente em sua dimensão pontual e global, visando a sua sustentabilidade para a geração presente e para as futuras gerações.

Destacamos (MACHADO, 2000; MILARÉ, 2000) as ações e intervenções necessárias à manutenção, preservação e restauração dos recursos socioambientais com vistas à sua utilização racional e disponibilidade permanente:

criar mecanismos e instrumentos para prevenir a poluição e agressões à natureza;

ajustar ou estabelecer ações e condutas que parem as atividades nocivas e promovam o equilíbrio entre atividades humanas e a natureza (educação socioambiental);

compreender e melhorar o mundo em que vivemos;

prevenir conflitos e/ou resolvê-los antecipadamente;

aprimorar as relações interpessoais e entre indivíduo(s), sociedade e natureza;

equacionar problemas e indicar condutas;

encontrar soluções criativas e éticas;

desenvolver a cidadania;

evidenciar o princípio do ambiente ecologicamente equilibrado como direito fundamental da pessoa humana.

Temos como premissa que o tripé desenvolvimento sustentável - cooperação entre os povos - educação socioambiental, resultado das intervenções éticas acima listadas, objetiva o resultado socioambiental ético como atitude natural, sentimento coletivo de responsabilização de valores, gestando o ambiente, agindo com intencionalidade sustentável.

\section{Direito da humanidade ao consumo sustentável e ecologicamente equilibrado: uma ética para a civilização da tecnologia e da informação}

A responsabilidade socioambiental, assim como o novo poder liberado pela tecnologia e pela informação, não se restringe à esfera do sujeito individual. Seu verdadeiro destinatário é a práxis coletiva, na qual a preocupação básica diz respeito aos efeitos remotos, cumulativos e irreversíveis da intervenção tecnológica sobre a natureza e sobre o próprio ser humano.

O poder tecnológico e a informação abrigam uma dimensão ameaçadora e perigosa. O risco encontra-se no sucesso extraordinário do poder tecnológico, o qual, aliado à informação, envolve a possibilidade de desfiguração da natureza e do ser humano, em função do exercício exacerbado do seu próprio poder.

A pretensão não é a transformação do homem (enquanto espécie) por intermédio da transformação das relações sociais, mas a preservação de sua essência contra os assaltos e desmedidas de seu próprio poder. O objetivo é reencontrar o ideal grego de medida, que vincula a ética à ideia de limite, moderação, contenção e austeridade. Segundo Boff (2011, p.116),

O ser humano precisa sentir-se natureza. Quanto mais mergulha nela, mais sente quando deve mudar e quando deve conservar em sua vida e em suas relações.

Benyus (1997), em sua obra sobre biomimética, propõe: 
A natureza como modelo, inspirando-se nela "para resolver os problemas humanos”. (p.8)

A natureza como medida, pois “após 3,8 milhões de anos de evolução, a natureza aprendeu: $\mathrm{O}$ que funciona. O que é apropriado. O que dura”. (p.8)

A natureza como mentora, pois "ela inaugura uma era cujas bases assentam não naquilo que podemos extrair da natureza, mas no que podemos aprender com ela”. (p.8)

Sob essas novas condições, o saber torna-se objeto de um imperioso dever, superando o papel que lhe fora atribuído pelas morais historicamente conhecidas, pois deve ser comensurável às virtualidades da extensão causal do agir humano coletivo, dando suporte a uma nova ética. Como isso não acontece, torna-se de extrema relevância ética o reconhecimento do desconhecido como contraface do dever e do saber, numa perspectiva de alteridade.

Considerando que o saber moderno, na forma das ciências da natureza e do progresso tecnológico que delas decorre, libera para o agir humano um potencial de forças tão extraordinário que produz uma transformação radical na essência desse agir, e que os efeitos da intervenção tecnológica estão investidos de um poder cumulativo de destruição, cujas consequências podem ser - e o são, de fato - irreversíveis, isso passa a incluir o conjunto da natureza na esfera de responsabilidade desse agir. Para Boff (2011, p. 34),

Um modo-de-ser não é um novo ser. É uma maneira do próprio ser de estruturar-se e dar-se a conhecer. O cuidado entra na natureza e na constituição do ser humano. O modo-de-ser cuidado revela de maneira concreta como é o ser humano.

Assim, não se trata apenas de prudência, mas de considerar a hipótese de um direito próprio, de uma autônoma significação ética da natureza, de sua inclusão, a título próprio, no domínio da ética e no horizonte de uma responsabilidade humana ampliada.

O novo imperativo ético não se dirige à ação do indivíduo isolado, mas ao agir coletivo. Seu destino não é a esfera das relações singulares, mas a do domínio da política pública, porque os efeitos do agir coletivo, na realidade, afetam a humanidade como um todo. Dessa forma, o que seria necessário fazer, para que o limite derradeiro não fosse imposto pela própria catástrofe, é alcançar uma potência de terceiro grau, isto é, uma nova posição de poder sobre o poder, tornado autônomo, que seria a superação da impotência em relação à compulsão autoimposta ao exercício tecnológico.

Esse é o desafio e, em resposta a ele, e sob a ameaça do apocalipse tecnológico, articula-se a proposta ética de Hans Jonas (1996) para a civilização tecnológica, salientando também que, em face da urgência e gravidade do tema, é necessário regulamentar, por meio de normas, o emprego efetivo dessa ética.

Para Jacobi (1998), a sustentabilidade confronta-se com o paradigma da "sociedade de risco”, colocando a necessidade de implementar práticas sociais baseadas no fortalecimento do acesso à informação e à educação socioambiental na perspectiva integradora. Justificamos assim a prática de sala de aula que traga à tona essas informações e formas diferentes de participar dos/as estudantes. Assim a sustentabilidade, na sua concepção, é um critério básico e integrador e necessita estimular constantemente as responsabilidades éticas, considerando que os aspectos econômicos não podem sobrepor-se à justiça social e à ética da vida. "A noção de sustentabilidade implica, portanto, uma interrelação necessária de justiça social, qualidade de 
vida, equilíbrio ambiental e a ruptura com o atual padrão de desenvolvimento" (JACOBI, 2003, p196).

Portanto, é fundamental a educação que, além de maior conhecimento, propicie mudanças, valores, práticas pedagógicas e políticas públicas que coloquem os/as estudantes e cidadãos/ãs como co-responsáveis para desempenharem ações básicas que favoreçam a harmonia dos indivíduos ou sujeitos com o ambiente.

A relação entre meio ambiente e educação para a cidadania assume um papel cada vez mais desafiador, demandando a emergência de novos saberes para apreender processos sociais que se complexificam em riscos ambientais que se intensificam. As políticas ambientais e os programas educativos relacionados à conscientização da crise ambiental demandam cada vez mais novos enfoques integradores de uma realidade contraditória e geradora de desigualdades, que transcendem a mera aplicação dos conhecimentos científicos e tecnológicos disponíveis. (JACOBI, 2003, p.196,)

Ao estimular uma educação voltada para o reconhecimento de outras formas de vida no planeta, o princípio da responsabilidade ou educação para a sustentabilidade estará possibilitando práticas interativas e dialógicas que culminarão na mudança de atitudes e comportamentos diante do consumismo de nossa sociedade. Poderemos, então, construir novos valores individuais e coletivos, a transformação esperada. Nesse sentido, Moraes (2008) propõe a expressão “ecologia dos saberes”, em visão integrada entre complexidade, transdisciplinaridade e educação. Refere-se "à existência de conhecimentos plurais, à importância do diálogo" entre diferentes saberes.
Morin (2000) destaca os sete saberes para uma educação efetiva, refere-se ao processo com visão integradora de totalidade, explorando novos ângulos até então não explorados pela pedagogia atual. Para ele, é de grande importância o desenvolvimento de uma identidade terrena na qual caberia à educação a missão ética de buscar e trabalhar uma solidariedade renovadora, que seja capaz de dar novo alento à luta por um desenvolvimento humano sustentável. Os sete saberes fundamentais com os quais toda cultura deveria trabalhar são: as Cegueiras Paradigmáticas, o Conhecimento Pertinente, o Ensino da Condição Humana, o Ensino das Incertezas, a Identidade Terrena, o Ensino da Compreensão Humana e a Ética do Gênero Humano.

Esses saberes são indispensáveis frente à racionalidade dos paradigmas dominantes, que deixam de lado questões importantes para uma visão abrangente da realidade. A educação tem por objetivo e preocupação ir muito além de simplesmente transmitir conhecimentos, uma prática cega em relação ao conhecimento humano. Sua prática, no entanto, decorrente da irresponsabilidade política, da falta de investimentos e da fragilidade da formação dos profissionais da educação, muitas vezes, ao invés de promover o conhecimento para a compreensão da totalidade, fragmenta-o, impedindo que o todo e as partes se comuniquem numa visão de conjunto e na perspectiva do pensamento complexo.

O destino planetário do gênero humano é ignorado pela educação. Precisamos, ao mesmo tempo, trabalhar a unidade da espécie humana de forma integrada com a ideia de diversidade. O princípio da unidade/diversidade deve estar presente em todas as esferas. Para tanto, torna-se necessário educar para os obstáculos à compreensão humana, combatendo o egocentrismo, o etnocentrismo 
e o sociocentrismo, que procuram colocar em posição secundária aspectos importantes para a vida das pessoas e das sociedades (MORIN, 2000).

Ceruti (1999) aponta a necessidade de elaboração de uma ecologia da civilização planetária que trabalhe com a "ética da vida" desenvolvendo a consciência planetária, configurando um estilo inédito de educação capaz de transformar o agir humano, articulando a relação entre ciência e ética. O projeto político de solidariedade defendido pelo autor unifica as diversas teorias normativas - "unidade na diversidade"-, propondo uma política de civilização do planeta Terra.

\section{Compartilhando e discutindo o fazer}

A temática da responsabilidade socioambiental na perspectiva do Princípio da Responsabilidade foi apresentada aos/às estudantes do Ensino Médio e Fundamental do CEEBJA Dr. Mário Faraco - Centro Estadual de Educação Básica de Jovens e Adultos de Curitiba (estudantes do sistema prisional) e com eles discutida, nas aulas de Biologia. Diferentes textos de apoio, dinâmicas e atividades de reflexão foram utilizados nessa abordagem de educação socioambiental. Alguns indicadores de mudanças na forma de pensar e agir desses estudantes estão contemplados neste artigo, pois as aulas permitiram a eles reflexões e questionamentos embasados nas teorias aqui discutidas.

Manifestações espontâneas dos/as estudantes nas aulas, tais como "a natureza nos ensina," "se todos fizessem a sua parte o mundo seria melhor," "nunca havia pensado a minha vida tão ligada a natureza," demonstram a importância do/a professor/a como mediador/a entre os conteúdos curriculares e as ressignificações construídas pelos estudantes. Vale lembrar que os/as estudantes em privação de liberdade, talvez pela baixa escolaridade da sua maioria, não valorizam os conhecimentos científicos como possibilidades de mudanças práticas em suas vidas.

[...] a educação ambiental na escola ou fora dela continuará a ser uma concepção radical de educação, não porque prefere ser a tendência rebelde do pensamento educacional contemporâneo, mas sim porque nossa época e nossa herança histórica e ecológica exigem alternativas radicais, justas e pacíficas. (JACOBI, 1998, p.43)

A frequência às aulas no sistema penitenciário, conforme depoimentos dos sujeitos, nem sempre está relacionada ao desejo de aprender, mas a "arejar a cabeça" e à busca da remissão da pena. No entanto, as aulas de Biologia, ao abordarem a educação socioambiental, possibilitaram outra motivação para a participação escolar. Ficaram evidentes a assiduidade dos/as alunos/as, a realização das tarefas e atividades escolares, a inserção de novos/as estudantes às aulas, a postura em sala de aula (retirada do capuz e visualização do rosto), a diminuição dos conflitos interpessoais e, principalmente, o fato de os/as estudantes soltarem a voz, ou seja, descobrirem que podem ter "voz e vez" em sala de aula.

Todo e qualquer exercício cognitivocomportamental interfere na autoestima e autoconfiança do/a estudante privado/a de liberdade e, por conseguinte, em seu processo de reinserção social. Para Morin (2010, p. 130):

O homem tem muitas dimensões e tudo o que desloca esse complexo é mutilante, não só para o conhecimento mas, igualmente, para a ação. Precisamos conceber que esse complexo que constitui o homem 
não é feito só de instâncias complementares mas de instâncias que são, ao mesmo tempo, antagônicas, e daí surge o problema da pluralidade dos imperativos éticos.

Salientamos a importância da educação e da escola prisional enquanto espaço/tempo/lugar de saberes e interrelações (conflitantes e conflituosas), um "microssistema" (BRONFENBRENNER, 1996) fundamental para o indivíduo em desenvolvimento, mesmo que "encurralado" pelas políticas educacionais do Estado, “com sua lógica homogênea e de competência, não levando em conta o tempo e a singularidade dos indivíduos e dos grupos” (BARBOSA; BORBA; ROCHA (Org.), 2003, p. 10-11). apresenta-se

A escola, no sistema penitenciário,

...como local de comunicação, de interações pessoais, onde o aprisionado pode se mostrar sem máscaras, afigura-se, portanto, como oportunidade de socialização, na medida em que oferece ao aluno, outras possibilidades referenciais de construção de sua identidade e de resgate da cidadania perdida. (ONOFRE, 2007. p. 27)

Seguindo o exemplo da sociedade humana, que se mostra como "um fenômeno social natural” em sua complexidade, a escola - e, por consequência, a educação emergem no sistema prisional como uma organização social de hipercomplexidade ${ }^{1}$. "A grande diversidade dos papéis sociais e dos estatutos a desempenhar permite o desabrochar das individualidades diferenciadas, quer no plano da inteligência, quer no plano da afetividade" (CÓRDOVA

\footnotetext{
1 "Um sistema hipercomplexo é um sistema que diminui suas restrições, ao mesmo tempo em que aumenta suas capacidades organizacionais, designadamente a sua aptidão para a transformação”. (MORIN, 1973, p. 115)
}

apud BARBOSA; BORBA; ROCHA; 2003, p. 28), quer no plano do poder, quer no plano do dever e dos direitos humanos.

Pérez (2007, p. 65) escreve sobre o paradoxo da educação no meio prisional:

Este espacio puede definirse como uma instituición total, esto ES, uma nstituición cerrada que pretende regular y vigilar todos los espacios de vida de um sujeto. Para ello instaura um conjunto de dispositivos que buscan observar La conducta de cada sujeto y someterla a evaluaciones para constatar si se registran o no câmbios respecto a lãs conductas que dieron lugar AL encierro de esse sujeto em La instituición. La clave está em que los espacios se unifican em um cuerpo noermativo único, que contextualiza $\mathrm{y}$ pauta lãs observaciones, que establece lãs sanciones a lãs transgresiones y que contabiliza como avances El cumplimiento normativo.

Trazer a discussão de temas socioambientais para o campo do ensino da Biologia no ensino prisional envolve desafios, competências e habilidades docentes para além do conhecimento específico de conceitos ecológicos, sociais e econômicos. Precisamos de humanidades, de fundamentos ontológicos e epistemológicos para aproximar os saberes científicos dos saberes vivenciais e da visão de mundo conforme a apreendemos. Para Puthoff (apud LASZLO, 2004, p. 40),

as interações nos domínios da natureza, assim como nos da mente, estão mediadas por um campo fundamental de informação presente no coração do universo.

O planeta chega, então, numa encruzilhada da responsabilidade,

representa a possibilidade de garantir mudanças sociopolíticas que não comprometam os sistemas ecológicos e sociais que sustentam as comunidades. (JACOBI, 2003) 
Ainda, com as aulas vivenciamos que:

A escola é um espaço onde as tensões se mostram aliviadas. O que justifica sua existência e seu papel na ressocialização do aprisionado. Inserida numa ordem que "funciona do avesso", oferece ao homem preso a possibilidade de resgate ou aprender uma nova forma de se relacionar, diferente das relações habituais do cárcere, contribuindo para a desconstrução da identidade de criminoso. (ONOFRE, 2007, p. 25)

\section{Considerações finais}

Percebemos que, embora o/a estudante esteja num lugar repressivo, privado de sua liberdade, consegue manter na sala de aula a valorização e a dimensão social da cidadania e responsabilização das ações ou agir humano.

Chegarmos ao século XXI com marcantes alterações climáticas, bem como relações conflituosas entre indivíduos de uma sociedade cada vez mais globalizada. Consideramos que a prática pedagógica com estudantes privados de liberdade possibilitou refletir sobre o nosso planeta, enquanto organismo vivo. A percepção de que Gaia está agonizando e coloca em risco a vida na Terra instiga todos, urgentemente, a modificar a sua forma de interação com a natureza, com a sociedade e, principalmente, consigo mesmos.

A complexidade dos processos de transformação causados pelo agir humano em relação aos recursos naturais e aos recursos afetivo-sociais colocou o planeta em risco socioambiental, causando danos a todas as formas de vida nele existentes.
A percepção do/a estudante privado/a de liberdade em relação a essas teorias conduziu-o/a a uma tomada de consciência de seu próprio agir. Ao perceber que as relações e interações humanas e sociais se constroem na própria convivência, abriu a possibilidade e o despertar para a participação como membro vivo e atuante com a responsabilização de si, dos seus atos e do cuidado com os recursos naturais existentes no planeta.

Educar os/as estudantes privados/as de liberdade, bem como a população de forma ampla, gerenciar práticas que informem a população e possibilitem a ela participar ativamente do cuidado com todas as formas de vida e com os recursos naturais, é uma necessidade. O desenvolvimento sustentável (por que não dizer, sócio-sustentável?) aparece para enfrentar a crise ecológica pela qual o planeta e toda a humanidade passam diante dos limitados recursos existentes.

O princípio da responsabilidade conclama para uma efetiva atuação humana de responsabilização individual e coletiva pelas práticas sociais. Esse aprendizado de interação com outras formas de vida e ecossistemas trabalhados em sala de aula no contexto dos/as alunos/as privados/as de liberdade mostra a dimensão possível da capacidade da escola e do poder público. Evidencia que, através da educação socioambiental, é possível superar a crise ambiental e implantar uma relação harmoniosa que promova a vida, a sustentabilidade para toda e qualquer forma de vida no planeta.

Assim, a educação no Sistema Penitenciário, bem como fora dele, e também a gestão dos recursos vivos, devem ser um processo permanente de aprendizagem que valoriza as diversas formas de conhecimento/vida e consegue formar cidadãos/ãs conscientes, com atuação socioambiental. Tudo isso repercute na sustentabilidade da vida 
no planeta e na forma de vida de cada estudante, na sua compreensão e forma de agir consigo mesmo, no mundo e com o mundo, aprendendo na experiência cotidiana o conceito vivencial de cidadania. Percebemos que a vida que pulsa lá fora, no espaço da educação socioambiental, é temática e pode ser contextualizada, mesmo que a paisagem vislumbrada seja restrita.

Estabelecer essa relação de sustentabilidade e responsabilidade apresentada pelos pensadores com quem dialogamos neste artigo instigou os/as alunos/as participantes a uma correlação, um despertar na sua condição de estudantes e cidadãos privados de liberdade, como se, pela compreensão das teorias discutidas, sua vida, carga emocional e existencial ficassem mais leves. Seu interesse em pensar e articular os conhecimentos científicos pareceu fazer mais sentido, pois, a partir das atividades desenvolvidas percebemos um maior envolvimento dos/as estudantes, uma crescente motivação em aprender e se colocar nas aulas.

Como Onofre (2007), consideramos que é possível ao professor criar afinidades, de forma a estabelecer "atmosfera de aula" segura, para que o conhecimento trazido pelo afetivo propicie ao aluno aprender de forma significativa.

\section{Referências}

AÑAÑOS, F. T. (Coord.). Las mujeres en las prisiones: la educación social en contextos de riesgo y conflicto. Barcelona: Gedisa, 2007.

BARBOSA, J.; BORBA, S.; ROCHA, J. (Org.). Educação \& complexidade nos espaços de formação. Brasília: Plano, 2003.
BENYUS, J. M. Biomimética: inovação inspirada pela natureza. São Paulo: Cultrix: Amana-Key, 1997.

BOFF, L. Saber cuidar: ética do humano, compaixão pela terra. 17. ed. Petrópolis: Vozes, 2011.

BRONFENBRENNER, U. A ecologia do desenvolvimento humano: experimentos naturais e planejados. Porto Alegre: Artes Médicas, 1996.

CÓRDOVA, R. A. Complexidade e multirreferencialidade em administração. In: BARBOSA, J.; BORBA, S.; ROCHA, J. (Org.). Educação \& complexidade nos espaços de formação. Brasília: Plano, 2003.

GIACÓIA Jr., O. Filosofia da crise ecológica. Cadernos de História e Filosofia da Ciência. Revista do Centro de Lógica, Epistemologia e História da Ciência, UNICAMP, Série 3, v. 6, n. 2, jul./dez. 1996. JACOBI, P. et al. (Orgs.). Educação, meio ambiente e cidadania: reflexões e experiências. São Paulo: SMA, 1998.

JACOBI, P. Educação ambiental, cidadaniae sustentabilidade. Cadernos de Pesquisa. Revista Eletrônica Scielo n. 118, USP, março, 2003. Disponível em: <http/www. scielo.br/pdf> . Acesso em: 10 jul. 2011.

JONAS, H. O princípio da responsabilidade: ensaio de uma ética para a civilização tecnológica. Cadernos de História e Filosofia da Ciência. Revista do Centro de Lógica, Epistemologia e História da Ciência. UNICAMP. Série 3, v. 6, n. 2. Filosofia da Crise Ecológica. jul./dez. 1996.

O princípio vida: fundamentos para uma biologia filosófica. Petrópolis: Vozes, 2004.

O princípio responsabilidade: ensaio de uma ética para a civilização tecnológica. Rio de Janeiro: Contraponto, 2006. 
LASZLO, E. La ciência y el campo akásico.

Madrid: Nowtilus, 2004.

MACHADO, P. A. L. Direito ambiental brasileiro. 8. ed. São Paulo: Malheiros, 2000.

MILARÉ, E. Direito do ambiente: doutrina, prática, jurisprudência, glossário. São Paulo: Revista dos Tribunais, 2000.

MORAES, Maria Cândida. Ecologia dos saberes:complexidade, transdisciplinaridade e educação: novos fundamentos para iluminar novas práticas educacionais. São Paulo: Antakarana/WHH, 2008.

MORIN, E. Os sete saberes necessários à educação do futuro. São Paulo: Cortez; Brasília: UNESCO, 2000.

MORIN, Edgar. Ciência com consciência. 14. ed. Rio de Janeiro: Bertrand Brasil, 2010.

ONOFRE, E. M. C. Educação escolar entre as grades. São Carlos: Edufscar. 2007.

PÉREZ, V. N. Espacio carcelario/espacios educativos. In: AÑAÑOS, Fanny T. (Coord.). Las mujeres en las prisiones: la educación social en contextos de riesgo y conflicto. Barcelona: Gedisa, 2007.

Enviado em: 19/09/2011

Aceito em: 08/11/2011 